\title{
EVALUATION OF LUMBOSACRAL ANGLE AMONGST CENTRAL INDIANS
}

\author{
Sonali Agichani', S. D. Joshi², S. S. Joshi ${ }^{3}$ \\ ${ }^{1}$ Assistant Professor, Department of Anatomy, Sri Aurobindo Medical College \& Post Graduate Institute, Indore. \\ ${ }^{2}$ Director Professor, Department of Anatomy, Sri Aurobindo Medical College \& Post Graduate Institute, Indore. \\ ${ }^{3}$ Director Professor, Department of Anatomy, Sri Aurobindo Medical College \& Post Graduate Institute, Indore.
}

\section{ABSTRACT}

\section{BACKGROUND}

Lumbosacral angle (LSA) or Sacrovertebral angle is clinically an important radiographic parameter related to the lordotic curve and is valuable in the management of patients with low back disorders. Its formation is related to evolution of bipedal gait and erect posture. It is defined as an angle between the body of the fifth lumbar vertebra and the base of the sacrum which measures about $120^{\circ}$ in normal adult. Reviewing the literature, it has been found that there is no conformity amongst the various workers regarding its definition and hence the methods of measurement, thus leading to variable values.

The present study aims to find the normal range of LSA in Central Indians.

\section{MATERIALS AND METHODS}

In the present descriptive study, LSA is measured in a) Ten cadavers (Age: 40-60 years) by Conventional method with goniometer and b) On digital radiographs of 200 lumbosacral spines (lateral view) by Conventional and Ferguson's technique digitally in the age groups of 31-40 years (Group I) and 41-50 years (Group II) in both the sexes.

\section{RESULTS}

a) In cadavers, the average angle was $131^{\circ}$ (Range: $110^{\circ}-150^{\circ}$ ); and b) In digital radiographs, mean angle by Conventional method was found to be $137.47^{0} \pm 8.44$ in males and $135.02^{\circ} \pm 8.61$ in females in group I. In group II, it was $133.11^{0} \pm 8.46$ in males and $133.65^{\circ} \pm 8.45$ in females. By Ferguson's method, it was $33.74^{0} \pm 7.65$ in males and $39.52^{\circ} \pm 7.17$ in females in group I and $38.27^{0} \pm$ 8.66 in males and $40.570 \pm 7.18$ in females in group II.

\section{CONCLUSION}

By conventional method, the average LSA was greater in males of group I. It decreased in Group II in both sexes. By Ferguson's technique, it was greater in females in both the age groups. It increased in group II in both the sexes. Apart from medicolegal importance, the knowledge of normal range of LSA in Central Indians is going to help the Orthopaedicians in the evaluation and treatment of low back pain. Measurement of LSA is also useful in the designing and development of spinal implants and instrumentation.

\section{KEYWORDS}

Lumbosacral Angle, Low Back Pain, Conventional Method, Ferguson's Method, Lumbar Lordosis.

HOW TO CITE THIS ARTICLE: Agichani S, Joshi SD, Joshi SS. Evaluation of lumbosacral angle amongst central Indians. J. Evolution Med. Dent. Sci. 2017;6(83):5797-5801, DOI: 10.14260/jemds/2017/1258

\section{BACKGROUND}

The lumbosacral region is the most important region of the vertebral column in terms of its mobility and weightbearing function. ${ }^{1}$ During the evolution of bipedal gait and erect posture, the lumbosacral part of vertebral column has undergone maximum modifications leading to the development of Lumbosacral angle (LSA). Deviations from normal and healthy erect posture result in corresponding changes in the lumbosacral angle. ${ }^{2}$ The lumbosacral curvature could be affected by conditions such as age, posture, degenerative changes, stature, trauma or surgery. It shows variations amongst races and ethnic groups. ${ }^{1}$

Normally the spine resists axial load and anterior shear forces at the lumbosacral junction ${ }^{3}$ but obesity leads to increase in shearing and compressive forces on the articular

'Financial or Other Competing Interest': None.

Submission 04-09-2017, Peer Review 03-10-2017,

Acceptance 09-10-2017, Published 16-10-2017.

Corresponding Author:

Dr. Sonali Agichani,

183, Kalani Nagar,

Airport Road, Indore.

E-mail: drsonaliagichani@gmail.com

DOI: $10.14260 /$ jemds/2017/1258 facets at lumbosacral junction ${ }^{4}$ thereby reducing its stability. ${ }^{3}$ Measurement of LSA is used to evaluate the stability of the lumbosacral region. ${ }^{4}$ Lumbar lordosis is defined as the anteriorly convex ${ }^{5}$ curvature assumed by the intact lumbar spine to compensate for the inclination of the sacrum and restore an upward orientation. ${ }^{6}$ As cited by Pun et al (1990), ${ }^{7}$ Farfan (1978) has shown that the presence of lordosis in lumbar spine has several biomechanical advantages and is essential for normal function. LSA is one of the clinically important radiographic angles related to this curve, and is frequently measured by Ferguson's technique. ${ }^{5}$ The lumbar spine in obese individuals becomes hyperlordotic leading to increased LSA, which becomes a risk factor for low back pain and poor posture. ${ }^{4}$

Going through the literature one is astonished about the fact that this angle has been variously defined and there is no uniformity in the methods of its measurement also.

Referring to the work of Ferguson, Maduforo et al (2012) ${ }^{8}$ has stated that this angle is formed between the long axis of lumbar vertebrae and the sacrum. It is sometimes defined as the angle formed between the superior surface of the sacrum and the horizontal plane. But according to Amonoo-Kuofi (1992), as cited by El Sayed et al $(2014)^{6}$ this is sacral inclination angle; and LSA is the angle between the plane of 
the inferior surface of the fifth lumbar vertebra and the upper surface of the sacrum. Faruqi $(2000)^{9}$ has described it as the angle between anterior surface of fifth lumbar vertebra and ventral surface of first sacral vertebra. It is approximately $210^{0}$. According to Datta $(2008)^{10}$, the prominence of Lumbosacral angle is due to more extensive anterior surface of the body of fifth lumbar vertebra and the intervertebral disc between L5 and S1, which is much thicker in front than behind. It measures about $120^{\circ}$ in normal adult. In long and slender individuals, LSA is often less than normal, and in short and thick subjects the angle may be exaggerated. ${ }^{10}$

Measurement of LSA is useful in the designing and development of spinal implants and instrumentation. ${ }^{1}$ The pathological angle values play a role in the induction of discopathy as well. ${ }^{11}$

\section{MATERIALS AND METHODS}

LSA can be measured by goniometry, radiography, flexible rulers, software methods, spinal mouse and inclinometer. Of all these methods, radiography remains the gold standard. ${ }^{5}$ In the present descriptive study, we have measured LSA in cadavers by goniometer and in lateral view radiographs of lumbosacral spine by digital method.

\section{For Cadaveric Study}

Ten adult cadavers (40-60 years) fixed in 10\% formalin were utilised. These were already dissected by the first-year students for routine dissection of abdomen and pelvis. The lumbosacral part of the vertebral column was separated in one piece by cutting a horizontal section at the thoracolumbar junction using a saw (Fig 1). These specimens contained the vertebral bodies with intervertebral discs from the upper border of L1 to the lower end of Sacrum including two hip bones. Lumbosacral angle was measured by goniometer (Fig 2). After recording the measurements, mean and range was calculated.

\section{For Radiological Study}

200 lateral view digital radiographs obtained from the Department of Radiodiagnosis were utilised after ethical clearance from the Institutional Ethical Committee. All radiographs were taken where the X-ray beam was centred on L3 with an anode film distance of $100 \mathrm{~cm}$. The magnification resulting from the use of this technique was negligible. ${ }^{6}$

Retrospective study was adopted in order to avoid issues like relatively high cost of the examination, and patient's irradiation, especially in females in their reproductive age. ${ }^{5}$ In the original article by Ferguson, the measurements of LSA were performed on recumbent lateral lumbar projections. However, Banks has suggested in later studies that the patient's position, whether upright on recumbent, is irrelevant in regard to this particular measurement. ${ }^{4}$ In the present study, LSA was directly measured digitally 1) by Conventional method (Fig 3) i.e. between the long axis of $5^{\text {th }}$ lumbar vertebra and that of first sacral vertebra and 2) by Ferguson's technique (Fig 4) i.e. between the base of the sacrum and the horizontal. Mean, Range (R) and Standard Deviation (S.D.) of LSA were calculated. These radiographs of lumbosacral spine belong to the age group of 31 to 50 years of both the sexes.
Observations were Tabulated (Table 1) and shown in bar diagram (Chart 1) by forming sub-Groups

1. $31-40$ years (Group I).
2. $41-50$ years (Group II).

Each subgroup had 50 males and 50 females.

\section{Statistical Analysis}

Apart from mean and standard deviation, unpaired $t$ test was done to analyse the statistical significance of age and gender differences. Statistically significant levels were considered to be $\mathrm{P}<0.05$.

\section{RESULTS}

In Cadavers, LSA was measured by Goniometer (Fig 2) and the readings were recorded. The average LSA was found to be $131^{0}$. It ranged between $110^{\circ}-150^{\circ}$.

\section{In Digital X-Rays}

LSA was measured digitally on 200 lateral view radiographs by Conventional method (Fig 3) and by Ferguson's technique (Fig 4). Mean, Range (R) and Standard Deviation (S.D.) were calculated. Observations were recorded by forming subgroups according to age and gender as seen in Table 1.

By Conventional method, Average LSA is found to be greater in males in group I and it decreased in the age group II. By Ferguson's technique, Average LSA is found to be greater in females in both the age groups and it increased in the age group II.

Unpaired $\mathrm{t}$ test was used to analyse the statistical significance of age and gender differences.

The difference of LSA measurements in 2 age groups is found to be significant statistically by both Conventional $(\mathrm{P}=0.018)$ and Ferguson's $(\mathrm{P}=0.013)$ methods.

The gender difference in LSA measurements is found to be significant statistically only by Ferguson's method $(\mathrm{P}=0.0003)$ and not by Conventional method $(\mathrm{P}=0.436)$.

\begin{tabular}{|c|c|c|c|c|}
\hline & Conventional Method & Ferguson's Method \\
\hline $\begin{array}{c}\text { Age } \\
\text { (Years) }\end{array}$ & Males & Females & Males & Females \\
\hline $31-40$ & $\begin{array}{c}137.47^{0} \pm 8.44 \\
\mathrm{R}(112-158)\end{array}$ & $\begin{array}{c}135.02^{0} \pm 8.61 \\
\mathrm{R}(116.162)\end{array}$ & $\begin{array}{c}33.74^{0} \pm 7.65 \\
\mathrm{R}(16.51)\end{array}$ & $\begin{array}{c}39.52^{0} \pm 7.17 \\
\mathrm{R}(26-59)\end{array}$ \\
\hline $41-50$ & $\begin{array}{c}133.11^{0} \pm 8.46 \\
\mathrm{R}(112-153)\end{array}$ & $\begin{array}{c}133.65^{0} \pm 8.45 \\
\mathrm{R}(116-151)\end{array}$ & $\begin{array}{c}38.27^{0} \pm 8.66 \\
\mathrm{R}(21-61)\end{array}$ & $\begin{array}{c}40.57^{0} \pm 7.18 \\
\mathrm{R}(26-57)\end{array}$ \\
\hline Table 1. Data Comparing Mean, S.D (Standard Deviation), \\
and Range(R) of LSA by 2 Methods - Conventional and \\
Ferguson's
\end{tabular}

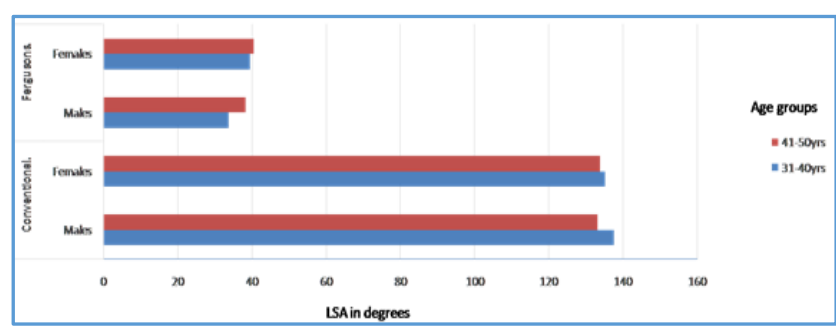

Chart 1. Clustered Bar Diagram showing Mean, S.D. (Standard Deviation), and Range(R) of LSA by 2 methods Conventional and Ferguson's. Blue bar $=31-40$ Years Age Group. Red bar $=$ 41-50 Years Age Group 


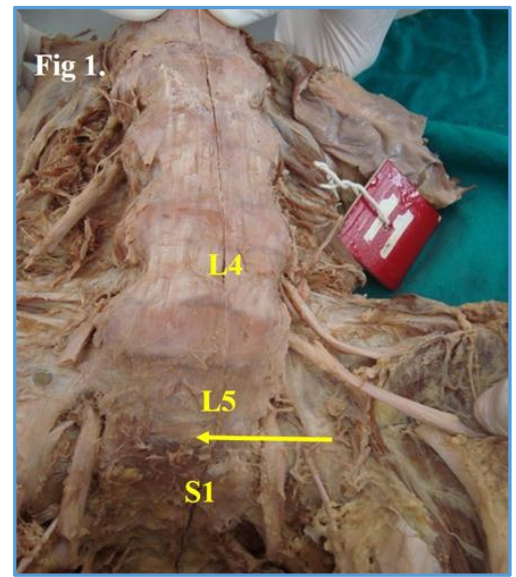

Figure 1. Cadaveric Specimen Showing Lumbosacral Junction. Lumbosacral Disc is Pointed by Yellow Arrow. L5$5^{\text {th }}$ Lumbar Vertebra. S1-1 ${ }^{\text {st }}$ Sacral Vertebra

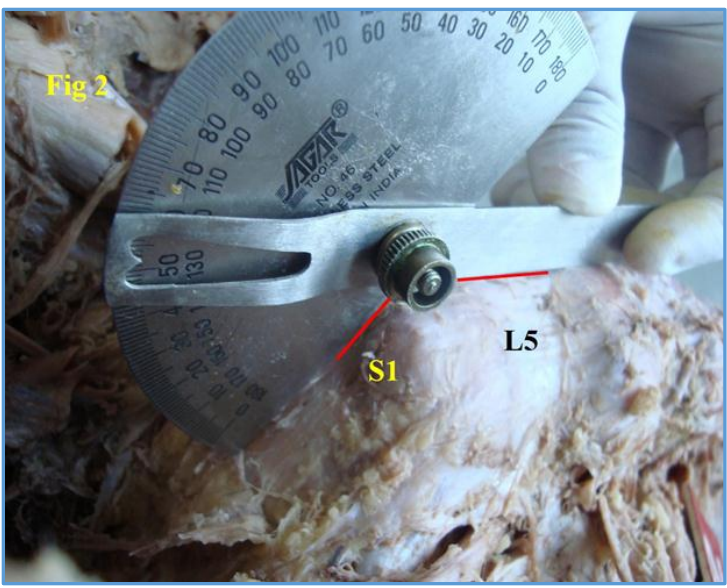

Figure 2. Measurement of LSA by Goniometer in Cadaveric Specimen. Two Arms of Goniometer are shown by Red Lines. L5-5 th Lumbar Vertebra. S1-1 st Sacral Vertebra

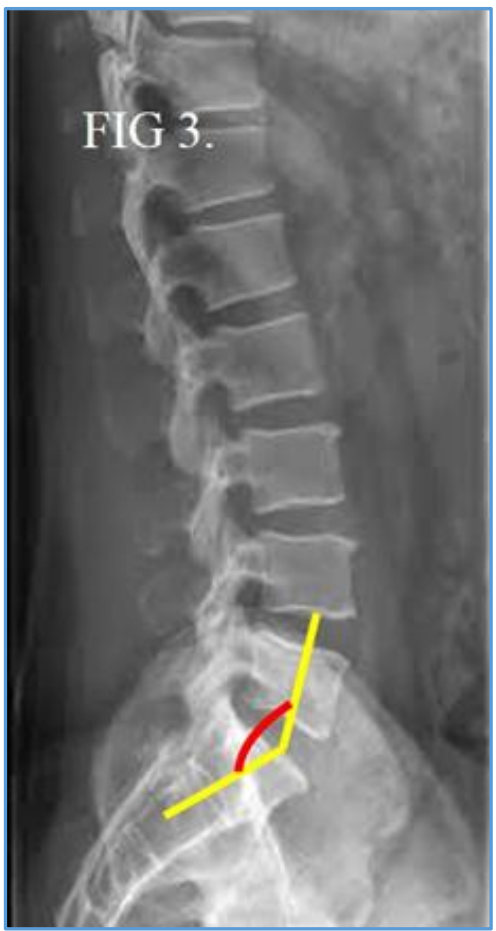

Figure 3. Measurement of LSA by Conventional Method on Digital Radiograph. LSA is shown between two Red Lines

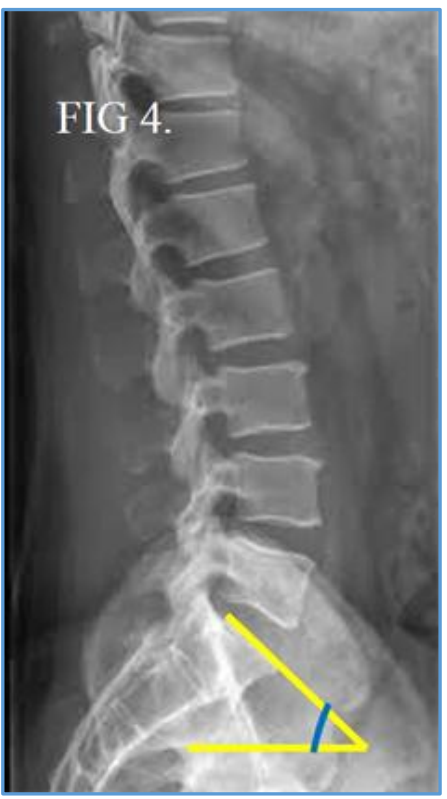

Figure 4. Measurement of LSA by Ferguson's Method on Digital Radiograph. LSA is Shown between Two Yellow Lines

\section{DISCUSSION}

Bipedalism and lumbar lordosis are often regarded as a cause of low back pain, through increased spinal shearing forces and increased risk of spondylolisthesis. ${ }^{12}$ Even with much anatomical modifications, some features of the human skeleton remain poorly adapted to bipedalism, leading to negative implications prevalent in humans today. The lower back and knee joints are plagued by osteological malfunction and lower back pain is a leading cause of lost working days. ${ }^{13}$

Amonoo Kuofi (1992) ${ }^{14}$ has stated that measurements of the curvature of lumbar spine are useful in the investigations of low back pain. Amongst the various angles measured, sacral inclination appeared to be a more important determinant of the degree of lumbar lordosis. It is same as the lumbosacral angle measured by Ferguson's technique in the present study. He also stated that the angle varied steadily with age, and had a tendency to decrease after the sixth decade, and further that the females had greater angle than males. As cited by Okpala (2014), ${ }^{5}$ Bryan is also of the same opinion regarding gender, which could be due to the increased secretion of a hormone called relaxin during the period of reproductive age. Our findings are in agreement with that of Amonoo Kuofi and Bryan. In the present study, LSA is found to increase with age in 41-50 years age group in both the sexes while Maduforo et al (2012) ${ }^{8}$ have found that it increases with age up to a maximum in the age group of 3640 years in their study on males of south-south Nigeria. It remained fairly constant thereafter until the seventh decade. This is rather surprising because advancing age is associated with loss of normal lumbar lordosis.

In their opinion, the lumbosacral angle measurement is significant in the evaluation of instability and low back pain in $3^{\text {rd }}$ to $6^{\text {th }}$ decades of life. The mean angle in their study was $36.1^{0} \pm 9.41^{0}$. It is found to be $36.01^{0} \pm 8.45$ in males in present study which matches very well with their findings. El Sayed et al $(2014)^{6}$, in a study on 30 Lebanese adult females in the age group of 18-22 years have also measured Sacral Inclination Angle (SIA) as described by Amonoo Kuofi (1992). Mean 
value of SIA in their study was $45.4^{\circ}$ and the mean LSA in females in our study is found to be $40.05^{\circ}$. This difference can be attributed to our bigger sample size, and difference in race, region and age. According to Maduforo et al (2012), ${ }^{8}$ the reason for the varying ranges of this angle even among a given race is not clear. However, constitutional build and activities of the muscles that act on the spine may be contributory. Okpala (2014) ${ }^{5}$ has referred to the findings of a large number of other workers in this field which confirms the degree of great variability of LSA.

In a study done by Endo et al (2010), as cited by El Sayed et al (2014),6 it has been reported that the degree of intervertebral disc degeneration increased in parallel with increase in sacral inclination angle while Ergun et al (2010) has reported that a more vertical orientation of the lumbosacral spine favours the development of disc degeneration and disc herniation, as documented in young adult women by magnetic resonance imaging. These agerelated normative values may help in directing physicians towards preventive or rehabilitation protocols.

Pate et al (1991) ${ }^{4}$ have stated that a wide range of normal values is documented in the literature, ranging from $26^{0}$ to $57^{0}$, the average being $41^{\circ}$ by Ferguson's technique. In the present study, it ranged between $16^{\circ}$ and $61^{\circ}$, the average being $38.03^{\circ} \pm 8.07$, thus providing values of normal lordosis for Central Indians. In a study done by Okpala (2014), ${ }^{5}$ LSA varied between $18^{\circ}$ and $71^{\circ}$, average being $44.5^{\circ} \pm 9.9$ for Southeast Nigerians. In his study, the average LSA for males was $43.4^{\circ}$ and for females was $45.5^{\circ}$. In the present study, average LSA for males is $36.01^{\circ}$ and for females it is $40.05^{\circ}$. LSA reported by Onyemaechi $(2016)^{1}$ ranged between $22^{\circ}$ and $64^{\circ}$ with a mean of $37.8^{0} \pm 9.2^{\circ}$, which matches very well with values found in present study. He found no correlation between LSA and age, sex, occupation or height of the subjects. Abittbol (1987) ${ }^{2}$, in a study on children up to 5 years of age, found that LSA increases from an average of $20^{\circ}$ at birth to an average of $70^{\circ}$ at 5 years and it remains constant thereafter. In his opinion also, LSA is not related to increase in age, height, weight or sex. These findings regarding age and sex corroborate well with the findings of Okpala. In a study by Hellems et al (1971),15 the overall mean was found to be $41.1^{0}$ with a standard deviation of $7.68^{\circ}$. They also found no significant difference in LSA among various age groups. This agrees with the fact that the development of the lumbar lordosis reaches a plateau at spinal maturity as mentioned by Okpala. ${ }^{5}$

Hughton et al (2015) ${ }^{16}$ while investigating the relationship between Lumbosacral Angle (LSA) and chronic low back pain (LBP) among females, have found significant positive correlations between degree of LSA and ageing; chronic LBP intensity; and LBP related functional limitation. Prolonged sitting at work was observed to increase the degree of LSA. Therefore, they suggested that it is imperative for Physiotherapists to emphasise on core lumbosacral stability activities among clients above 50 years with LSA above 30 degrees.

Stagnara et al (1982) have measured the lumbosacral angle and found it to be $21^{0}$ (range $10^{0}-35^{\circ}$ ). Referring to these values, Pun et al (1990) 7 in their retrospective study on review of 26 patients treated for tuberculosis of lumbosacral junction have concluded that kyphosis or hypolordosis $\left(<10^{\circ}\right)$ is associated with higher incidence of back pain. Hence, it is important to preserve the normal angle and minimise the chances of developing kyphosis during treatment. According to Briggs et al (2004), ${ }^{17}$ vertebral fracture is associated with a decrease in lumbar lordosis. Azar et al (2010)18 have concluded that abnormal lumbosacral angle is not associated with the incidence of low back pain.

Nakipoglu et al (2008) ${ }^{19}$ have measured sacral horizontal angle (SHA) between the base of sacrum and the horizontal plane. It is equivalent to LSA measured by Ferguson's technique in the present study. They have found no statistically significant difference in SHA between acute and chronic low back pain patients. Referring to the work of Harrison et al (1998), they have stated that hypolordosis is found in patients with chronic LBP whereas the acute back pain group was hyperlordotic. They have also referred to the work of Jackson et al (1994) who reported that lumbar lordosis was significantly lower and is not related to age or gender in chronic back pain patients. As lumbar lordosis increases, SHA also increases. Metgud et al $(2016)^{3}$, in a study on 30 participants with low back pain, while assessing the effect of body mass index, central obesity and core muscle activation on spinopelvic parameters, found that there is weak core muscle activation in them, which in turn leads to an increase in lumbosacral and pelvic inclination angle. Pate et al (1991), ${ }^{4}$ have stated that unfortunately, there is no definite consensus of opinion as to the exact significance of either a decreased or increased lumbosacral angle, partly because of the large variability and range of normal values. Moreover, these normal figures are of possible forensic importance because of the observed racial, ethnic and regional variations. ${ }^{6}$

\section{CONCLUSION}

After a detailed study of LSA, and comparing these with the findings of other workers in the field, it becomes obvious that there is no unanimity in the definition of LSA and the average value including the range arrived at is very variable. This can possibly be due to the racial variation or may be related to the age and sex. It seems probable that the value of LSA is also dependent on weight and stature. The LSA values (38.030 \pm 8.07 ) arrived at in the present study reflect the average for the Central Indian population and is of significance to the radiologist, orthopaedician and physiotherapist dealing with low back pain.

\section{REFERENCES}

[1] Onyemaechi NOC. Evaluation of lumbar angles and their clinical correlates in a Nigerian population. Int J Res Med Sci 2016;4(6):2018-23.

[2] Abittbol MM. Evolution of the lumbosacral angle. American Journal of Physical Anthropology 1987;72(3):361-72.

[3] Metgud S, Naik S, Heggannavar A. Effect of body mass index, central obesity and core muscle activation on pelvic inclination and lumbosacral angle in individuals with low back pain: an observational study. International Journal of Physiotherapy and Research 2016;4(3):1535-9.

[4] Pate D. Stability of the Lumbar Spine. Dynamic Chiropractice 1991;9(11):1-3.

[5] Okpala F. Measurement of lumbosacral angle in normal radiographs: a retrospective study in 
Southeast Nigeria. Ann Med Health Sci Res 2014;4(5): 757-62.

[6] El Sayed S, Saab IM, EI Shishtawy M, et al. Morphometric study of the lumbosacral spine and some of its related angles in Lebanese adult females. IJAE 2014;119(2):92-105.

[7] Pun WK, Chow SP, Luk KD, et al. Tuberculosis of the lumbosacral junction. J Bone Joint Surg $\mathrm{Br}$ 1990;72(4):675-8.

[8] Maduforo C, West O, Nwankwo N, et al. Study of the Lumbosacral angles of males in Port Harcourt, SouthSouth Nigeria. The Nigerian Health Journal 2012;12(1):22-4.

[9] Faruqi NA. Human Osteology-a clinical orientation. $2^{\text {nd }}$ edn. New Delhi, India: CBS Publishers and Distributors 2000: p. 208.

[10] Datta AK. Essentials of human anatomy. Thorax and abdomen. $8^{\text {th }}$ edn. Lenin Saranee, Kolkata: The Indian Press Pvt Ltd., 2008: pgs. 143, 393.

[11] Bene E. Measurement of the lumbosacral angle and its clinical significance. Z Rheumatol 1981;40(3):149-52.

[12] Wagner H, Liebetrau A, Schinowski D, et al. Spinal lordosis optimizes the requirements for a stable erect posture. Theoretical Biology and Medical Modelling 2012;9:13.
[13] Human skeletal changes due to bipedalism. En Wikipedia.org/wiki/Human skeletal changes due to bipedalism. 2012.

[14] Amonoo-kuofi HS. Changes in the lumbosacral angle, sacral inclination and the curvature of the lumbar spine during aging. Acta Anatomica (Basel) 1992;145(4):373-7.

[15] Hellems HK, Keates TE. Measurement of the normal lumbosacral angle. Am J of Roentgenology 1971;113(4):642-5.

[16] Hughton A, Adu-Gyamfi A. The relationship between lumbosacral angle and chronic low back pain among females.

Www.journal.physioghana.org/index.php/scientific congress/article/view/18. 2015.

[17] Briggs AM, Greig AM, Wark JD, et al. A review of anatomical and mechanical factors affecting vertebral body integrity. Int J Med Sci 2004;1(3):170-80.

[18] Azar MS, Talebpour F, Alaee AR, et al. Association of low back pain with lumbar lordosis and lumbosacral angle. J Mazand Univ Med Sci 2010;20(75):9-15. (Persian).

[19] Nakipoglu GF, Karagoz A, Ozgirgin N. The biomechanics of the lumbosacral region in acute and chronic low back pain patients. Pain Physician 2008;11(4): 505-11. 